\title{
Water Quality and Sediment Profile in Shrimp Culture with Different Sediment Redox Potential and Stocking Densities Under Laboratory Condition
}

\author{
Wiyoto $^{1,2 *}$, Sukenda $^{1}$, Enang Harris ${ }^{1}$, Kukuh Nirmala $^{1}$ and Daniel Djokosetiyanto ${ }^{1}$ \\ ${ }^{1}$ Department of Aquaculture, Faculty of Fisheries and Marine Science, Bogor Agricultural University \\ Jl. Lingkar Kampus IPB Darmaga, Bogor, Jawa Barat 16680 \\ 2Production Technology and Management of Aquaculture, Vocational Study Program, Bogor Agricultural University \\ Kampus IPB Cilibende, Jalan Kumbang No 14, Bogor, Jawa Barat 16151 \\ Email : wiyoto2001@yahoo.com
}

\begin{abstract}
Sediment quality has been considered as one of the prime factors influencing the environment quality that support maximum shrimp production. The aim of the study was to evaluate the effects of sediment redox potential and shrimp stocking density on the profile of some sediment and water quality parameters. Two factors randomized factorial design was applied, with stocking density (60 and 120 shrimps. $\mathrm{m}^{-2}$ ) as the first variable and sediment redox potential (-65 mV, -108 mV and -206 mV) as the second variable. Some significant changes in TP, total $\mathrm{Mn}$, and total $\mathrm{S}$ concentrations in the sediment were observed after the experimentation $(P<0.05)$. Sediment redox potential significantly affected the dissolved oxygen, $T A N, \mathrm{NO}_{2}, \mathrm{NO}_{3}$, and $\mathrm{H}_{2} \mathrm{~S}$ concentrations in the water. Whereas shrimp stocking density affected all water quality parameters except $\mathrm{H}_{2} \mathrm{~S}$ concentration. Significant interactions between redox potential and stocking densities were observed in the nitrite and alkalinity concentrations. The significant effects of both shrimp density and redox potential on the sediment and water parameters in particular those that are known to directly affect the shrimp welfare (e.g. oxygen, ammonia, nitrite and $\mathrm{H}_{2} \mathrm{~S}$ ) indicate that these variables are of important aspects in shrimp pond management. Furthermore, the results clearly showed that $-206 \mathrm{mV}$ redox potential significantly reduced the dissolved oxygen concentration in the sediment-water interface and increased the generation of $\mathrm{H}_{2} \mathrm{~S}$ in water column. Thereby, this redox potential level is not advisable for shrimp culture system.
\end{abstract}

Keywords: redox potential, stocking density.

\section{Introduction}

Shrimp farming has become one of the most important aquaculture sectors, including in Indonesia. Indonesian shrimp production has been dramatically increasing during the last decade, from 184.616 MT on 2003 to 551.507 MT on 2013 or about 199\% increase (FAO, 2015). However, despite the progressive increase in production, shrimpfarming industry still encounter some major challenges among which disease outbreak, which has caused significant losses to the industry. For instance, in 2011 China suffered devastating economic losses due to outbreaks of EMS outbreak, accounting for about $80 \%$ production, especialy at farms with more than five year (Leaño and Mohan, 2012). New diseases outbreak have been reported recently including new lethal variant of YHV (YHV-8), covert mortality nodavirus (CMNV) (Flegel, 2015), and the acute hepatopancreatic necrosis disease (AHPND) that caused large-scale mortality of cultivated shrimp in several countries in Asia (FAO, 2013; NACA, 2014) and South America (Flegel,
2015). The impact of AHPND alone has affected about 39000 ha of shrimp farms in Mekong Delta, Vietnam and caused about USD 1 billion losses in Asia (FAO, 2013).

Disease outbreak and environmental quality in shrimp culture system are closely related. Environmental quality in aquaculture system promotes the emerging of disease both by facilitating the proliferation of pathogens and compromising the susceptibility of the animal against the disease (Mydlarz et al., 2006). It has been hypothesized that viral and bacterial diseases, together with poor soil and water quality, were the main causes of the reported shrimp mass mortality in several studies (Walker and Winton, 2010). The deterioration in environmental quality as well as environmental perturbation could lead to stress in the cultured animal, which eventually is reducing their immunity (Ellis, 1992). On the other hand, the rate of environmental quality deterioration in shrimp culture system seems to depend on the intensity of farming and the culture age. The high shrimp density 
leads to the increase of nutrient loading from feeding, and accordingly the increase of waste from the unconsumed feed, fecal materials and metabolic processes, which accumulates in the water and the sediment. Without any water and sediment treatment, the high waste accumulation ultimately increases the concentration of various toxic compounds and generates some major changes in both water quality and pond sediment, which may cause physiological stresses and reduce the shrimp immunity. Moreover, the high nutrient waste could also promote the growth of opportunistic pathogens (De Schryver and Vadstein, 2014), and therefore increasing the opportunity of disease outbreak (Blancheton et al., 2013).

As most shrimp pond is earthen pond (Krummenauer et al., 2010; Lin et al., 2010), pond sediment plays an important role in the shrimp culture environment. The shrimp pond sediment is of particular important because as a benthic organism, shrimp spend most of their time in the soil-water interface environment. Therefore, any change in this environment could have direct effects on the shrimp condition (FAO, 2013) including increasing the risk of bacterial disease outbreak (Nimrat et al., 2008). On the other hand, most of the organic materials and waste products from the farming activity accumulate in the pond sediment and may also contribute to the deterioration of the water quality (Saraswathy et al., 2013; Yuvanatemiya and Boyd, 2006).

Accumulated sediments in shrimp ponds are highly reduced, enriched in organic and inorganic matters. Approximately $24-55 \%$ of the nitrogen and $42-84 \%$ of the phosphorus from the feed not recovered in harvested shrimp was found in the pond bottom (Casillas-Hernández et al., 2006; Sahu et al., 2013). The level of nutrient accumulation in shrimp pond sediment appears to be under the influence of the culture intensity and the culture age. Paez-Osuna and Ruiz-Fernandez (2005) described that nitrogen loads from shrimp farms ranging from $31 \mathrm{~kg} \mathrm{~N} \cdot \mathrm{ha}^{-1}$ cycle for extensive farms to $672 \mathrm{~kg}$ N.ha-1 cycle for intensive farms. On the other hand, the total concentrations of inorganic nutrients such as $\mathrm{S}, \mathrm{P}$, and $\mathrm{Mn}$ in the sediment were progressively increasing with the culture period (Ritvo et al., 1998). Likewise, Biao and Kaijin (2007) reported that total organic carbon of the shrimp pond sediments accumulates over time, and has positive linear relation with the pond age.

The accumulation of waste materials in the pond sediment generates a favourable nutrient rich environment for the microbes. These microbes consume significant amount of oxygen and thereby causing anoxic condition in the sediment
(Avnimelech and Ritvo, 2003; Molnar et al., 2013). When oxygen concentration is limited, the microbes will use other terminal electron acceptors for organic matter decomposition. However, anaerobic decomposition in the pond bottom could lead to the production of reduced and potentially toxic compounds including ammonia, hydrogen sulphide, methane and some organic acids (Zhou et al., 2009). Thus, anaerobic environment in the pond sediment could negatively affect shrimp production both due to the unfavourable condition for the shrimp and the diffusion of the toxic compounds from the sediment to the water column (Zhou et al., 2009). The degree of anaerobic condition in pond sediment can be determined by measuring redox potential that is an index of the degree of oxidation or reduction in chemical system (Wilding, 2012). Redox potential represents the intensity of the pond anaerobic conditions, which decreases in time and could affect the dominant microbial transformations of substances, the toxin production and mineral solubility (Avnimelech et al., 2004). According to its redox potential, pond soil can be categorised into four groups, i.e oxidized, 400-700 mV; moderately reduced, 100-400 mV; reduced, -100-100 mV; and highly reduced, -300- -100 mV (Chien, 1989). The highly reduced sediment indicates the wide layer of anaerobic zone in the pond bottom, which might rise upward to the surface of the soil (Boyd, 1995), increase the sediment oxygen demand and affect the water column (Avnimelech and Ritvo, 2003). Increasing sediment oxygen demand can caused decreasing or inhibiting of grow fish (or shrimp) (Avnimelech and Ritvo, 2003). The present study evaluates the effects of sediment redox potential and shrimp stocking density on the profile of some sediment and water quality parameters. The results of this study can be used to determine a tolerable range of redox potential in relation to the shrimp stocking density.

\section{Materials and Methods}

\section{Experimental setup}

Two factors randomized factorial design was applied with stocking density as the first variable and sediment redox potential as the second variable with 3 replications. Two different stocking densities, 60 shrimps. $\mathrm{m}^{-2}$ (LD) and 120 shrimps. $\mathrm{m}^{-2}$ (HD), and three redox potentials, i.e. $-65 \mathrm{mV},-108 \mathrm{mV}$ and $206 \mathrm{mV}$ were tested.

Eighteen units of fibre tanks with a dimension of $48 \mathrm{~cm} \times 48 \mathrm{~cm} \times 100 \mathrm{~cm}$ were used as the experimental containers. On the bottom of each tank, different soil substrate was added at $5 \mathrm{~cm}$ thickness according to the redox potential 
treatments. Soil substrate with the highly negative redox potential was obtained from a 2 years old shrimp pond in Lampung, Indonesia with a redox potential of $-206 \mathrm{mV}$. As for other redox potential treatments, the soil substrate were obtained by mixing the highly negative redox potential shrimp pond sediment with positively redox potential dry soil $(251 \mathrm{mV})$ which was obtained from dry the local area in Bogor at different ratio according to the target values, i.e. 9:1 for the $-65 \mathrm{mV}$ and $4: 1$ for the -108 $\mathrm{mV}$. The measurement of redox potential was carried out in triplicates according to Arsana et al. (2003) using an ORP meter (Trans Eco). The tanks were subsequently filled with filtered seawater at a depth of $85 \mathrm{~cm}$. Aeration for all tanks was provided by aeration line installed just above the soil surface that was connected to an air blower at a flow rate of $5.10 \pm 0.14$ L.S $^{-1}$. Water salinity and temperature in each tank was maintained constant at $28 \pm 2$ g.L-1 and $29 \pm 1{ }^{\circ} \mathrm{C}$.

Pacific white leg shrimp Litopenaeus vannamei post larvae (PL12) were obtained from a local hatchery at Banten Province, Indonesia and were cultured for 8 weeks until they reached an average body weight of $5.32 \pm 0.22 \mathrm{~g}$. Healthy shrimp at intermolt phase were selected and randomly distributed to each tank at the density according to the treatments. Feeding was performed using 35\% crude protein commercial shrimp feed at a daily level of $4.4 \%$ based on body weight and adjusted according to sampling result offered 3 times daily for 35 days of experimentation period.

Five hundred grams of soil samples was collected from each experimental tank at the initial and the final day of experimentation. The dissolved oxygen (DO) concentration, temperature, $\mathrm{pH}$ and salinity of the culture water were measured daily at 07:00h. Temperature and dissolved oxygen concentration were observed at 5 different depths, i.e. $10 \mathrm{~cm}, 50 \mathrm{~cm}, 75 \mathrm{~cm}, 80 \mathrm{~cm}$, and $85 \mathrm{~cm}$ from the water surface. Water samples were also collected weekly to measure the concentrations of total ammoniac nitrogen (TAN), $\mathrm{NO}_{2}, \mathrm{NO}_{3}$, and total alkalinity.

\section{Physical and chemical analyses}

Organic C in soil was measured according to the procedures described in Rayment and Higginson (1992). Briefly, to $0.5 \mathrm{~g}$ of soil sample $5 \mathrm{~mL} 1 \mathrm{~N}$ $\mathrm{K}_{2} \mathrm{Cr}_{2} \mathrm{O}_{7}$ was added and homogenized. Subsequently, $7.5 \mathrm{~mL}$ of concentrated $\mathrm{H}_{2} \mathrm{SO}_{4}$ was added, homogenized and allowed to stand overnight. The optical density of the supernatant was then measured at $561 \mathrm{~nm}$ wavelengths. Kjeldahl $\mathrm{N}$ was measured to determine total organic $\mathrm{N}$ in the soil according to the procedure described in USDA
(2014). Total P (TP), total S (TS), Fe, and Mn in soils were measured in soil extract obtained from perchloric digestion (Horwitz, 2002). Total phosphorus in the soil extract was determined by ascorbic acid methods. Total $\mathrm{S}$ was determined by adding $7 \mathrm{~mL}$ of acid solution $\left(50 \mathrm{~mL}\right.$ of $\mathrm{CH}_{3} \mathrm{COOH}, 20$ $\mathrm{mL}$ of concentrated $\mathrm{HCl}, 20 \mathrm{~mL}$ of concentrated $\mathrm{H}_{3} \mathrm{PO}_{4}$ and $2.5 \mathrm{~mL} \mathrm{BaCl}_{2}$-tween, dissolved in $1 \mathrm{~L}$ of deionized water) to $1 \mathrm{~mL}$ of the soil extract followed by optical density measurement at $494 \mathrm{~nm}$. Total Fe and $\mathrm{Mn}$ in soil were measured directly from the soil extract solution by using Atomic Absorption Spectroscopy (AAS). Dissolved oxygen and temperature in water were measured in situ using DO meter (Lutron D0-5510), whereas pH and salinity were measured using $\mathrm{pH}$-meter (Trans Eco) and refractometer (ATAGO Master-S/Mill $\alpha$ ), respectively. Total ammoniacal nitrogen, nitrite, nitrate and alkalinity were measured using the methods described in the Standard Methods for Water and Wastewater Assessment (APHA, 2012).

\section{Statistical Analyses}

All proportional data was arcsine transformed. Homoscedasticity and normality of all data were assessed using Levene's test and a KolmogorovSmirnov test, respectively, and square root transformation was performed to the data that did not meet these assumptions. Phosphorus, sulphur and manganese concentrations data were analysed using non-parametric Kruskal Wallis test and followed by Mann Whitney non-parametric post-hoc test. Analyses of variance (ANOVA) were used to analyse the difference in soil composition at the initial and after experimentation at each redox potential and the difference of initial dissolved oxygen concentration in the water. Paired t-test was used to analyse the difference of dissolved oxygen concentrations between the initial and final day of experiment for each treatment. Repeated measures ANOVA using the linear model of three factors (stocking density, redox potential and time) was used to analyse the effect of sampling time on $\mathrm{pH}$ and the concentrations of DO, TAN, nitrite, nitrate, alkalinity and $\mathrm{H}_{2} \mathrm{~S}$. Statistical analyses were conducted using SPSS statistics version 20 for windows (SPSS Inc.) at a significance level of 0.05 . Significant differences between treatments were determined using a post-hoc Duncan test.

\section{Results and Discussion}

\section{Sediment profile}

The total organic $\mathrm{C}$ and $\mathrm{N}$ in the sediment were not significantly different $(P>0.05)$ amongst treatments (Figure 1.). There is a tendency of organic $\mathrm{C}$ and $\mathrm{N}$ increase with the stocking density; 
the differences however were not significant. The insignificant difference in the total organic $\mathrm{C}$ between the initial and after experimentation may indicate that most of the $\mathrm{C}$ from the feed accumulated as $\mathrm{CO}_{2}$ and therefore diffused out from the water (Xinglong and Boyd, 2006). Furthermore, the concentrations of organic $\mathrm{C}$ in this study were in the range normally found in aquaculture ponds (Xinglong and Boyd, 2006).

There were sharp decreases $(P=0.018$ for redox potential $-65 \mathrm{mv}, \mathrm{P}=0.020$ for redox potential $108 \mathrm{mV}$ and $\mathrm{P}=0.021$ for redox potential $-206 \mathrm{mV}$ ) of TP concentrations in the sediment after 35 days of experimentation that were observed in all redox potential treatments (Figure 2a.). However, on the final day of experimentation no significant $(P>0.05)$ difference was observed between the low and high shrimp stocking density regardless the redox potential of the sediment. Significant reductions of TP in the sediment were observed in all redox potential treatments. Higher reduction level was observed in the $-65 \mathrm{mV}(\mathrm{P}=0.018)$ and $-108 \mathrm{mV}$ $(P=0.020)$ sediment, which mainly due to the higher initial TP concentration in these treatments compared to that in $-206 \mathrm{mV}$ sediment. The difference in the initial concentration of TP between sediments may be attributed to the redox condition and the $\mathrm{pH}$ value. The adsorption of phosphate in anoxic sediment (highly negative redox) was reported to be lower than that in oxic sediments because the iron oxyhydroxide that are important in the adsorption of phosphate in oxic sediment are converted to iron sulphides in anoxic sediments (Nóbrega et al., 2014). Phosphorus concentration in the sediment is also sensitive to $\mathrm{pH}$ changes. Acidic soils contain primarily $\mathrm{H}_{2} \mathrm{PO}_{4}$, which may reacts with iron and aluminium to form highly insoluble compound (Boyd, 1995). Indeed, at high pH the rate of $\mathrm{P}$ co-precipitation with $\mathrm{Ca}$ and $\mathrm{CO}_{3}{ }^{2-}$ tends to increase, however this is most pronounced at $\mathrm{pH}$ level of more than 9.5, which was beyond the $\mathrm{pH}$ range in this experiment (Sindelar et al., 2015).

Significant reductions in total $\mathrm{Mn}$ concentrations were observed in the sediment with $65 \mathrm{mV}(\mathrm{P}=0.035)$ and $-108 \mathrm{mV}(\mathrm{P}=0.040)$ redox potential at the final day of experimentation. However, no significant difference $(P>0.05)$ was observed between stocking densities. There was no significant difference of total $\mathrm{Fe}$ concentration between initial and the final experimentation day as well as between the stocking densities $(P>0.05)$. The main processes considered to involve in the redox cycles of $\mathrm{Mn}$ and $\mathrm{Fe}$ in oxic and anoxic environment are the dissolve of reduced forms of the metals in suboxic or anoxic seawater, and the oxidation of the reduced ions at the upper part of water column with oxygen or other oxidants resulting oxidized particulate forms of the metals that sink back to the sediment (Pakhomova et al., 2007). However, the utilization of $\mathrm{Mn}$ and $\mathrm{Fe}$ oxides as an electron acceptor for microbial anaerobic respiration, i.e. the reduction of these oxides, is not likely when oxygen supply and/or nitrate concentration is still available in the environment (Boyd, 1995). This might explain the lower initial concentrations of total $\mathrm{Mn}$ and total $\mathrm{Fe}$ in the $-206 \mathrm{mV}$ sediment, which was highly reduced, compared to those in other sediments.

Some significant reductions in total $\mathrm{Mn}$ concentrations specifically in the -65 and $-108 \mathrm{mV}$ sediments that were observed on the final day of experimentation were likely attributed to the release of the reduced $\mathrm{Mn}$ oxide into the water column. Indeed, the reduction of $\mathrm{MnO}_{2}$ that leads to the escape of $\mathrm{Mn}^{2+}$ from the sediment seems to be less likely as the DO concentrations at the surface of the

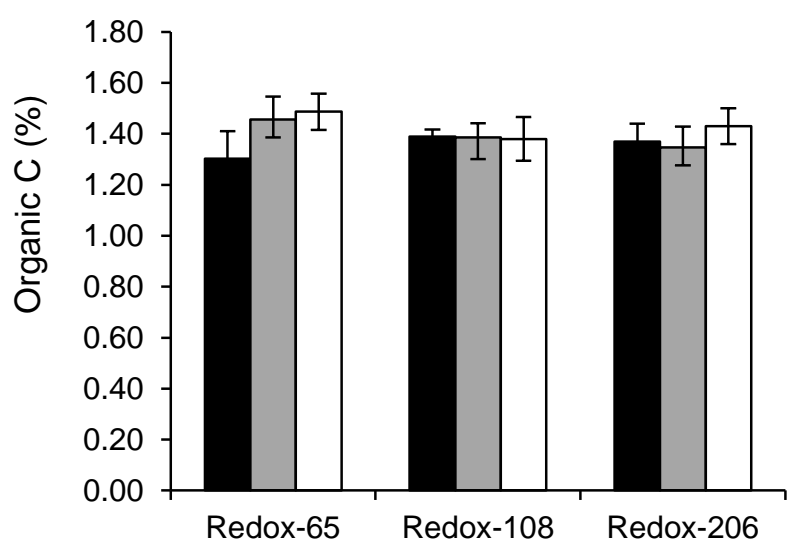

(a)

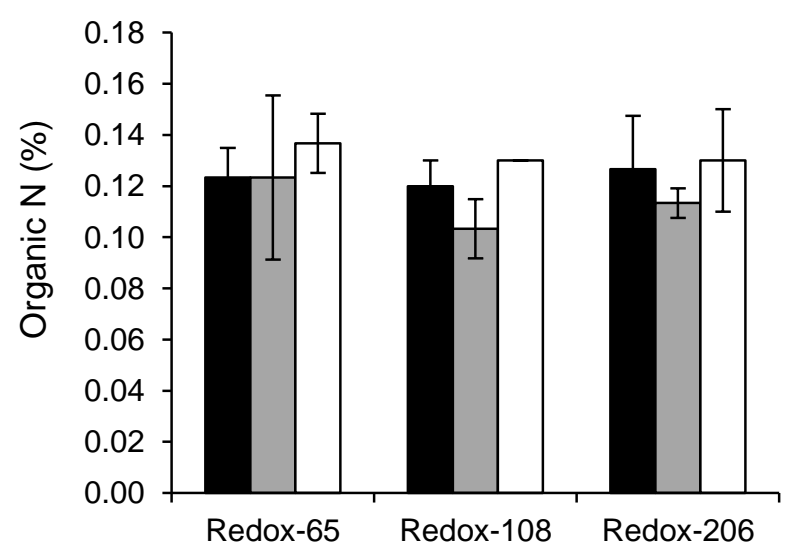

(b)

Figure 1. The concentrations of organic carbon (a) and nitrogen (b) in the sediment with different redox potential and shrimp stocking densities at the initial and day-35.

Note. $\square=$ Initial; $\square=\mathrm{LD} ; \square=\mathrm{HD}$ 

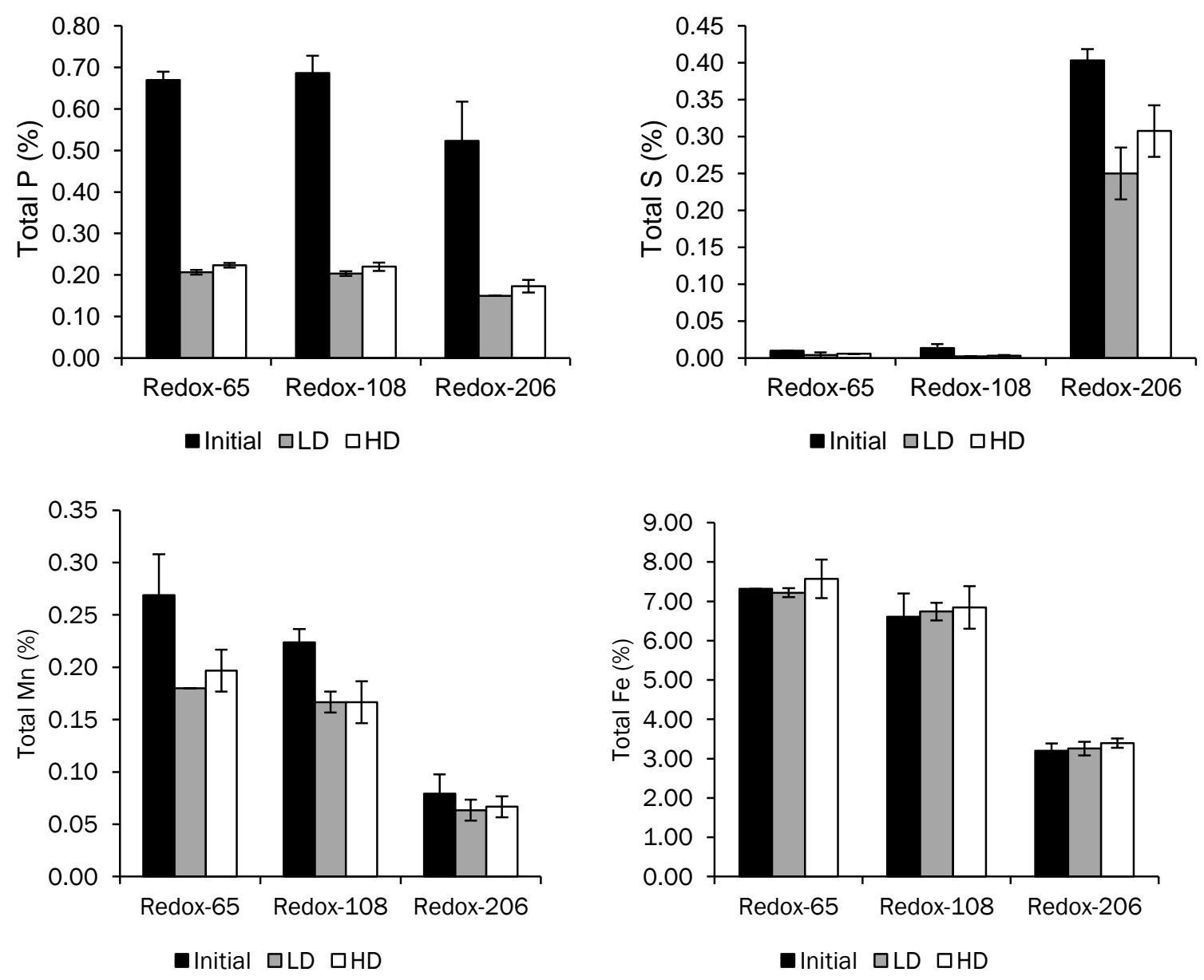

Figure 2. The concentrations of total $\mathrm{P}, \mathrm{S}, \mathrm{Mn}$ and $\mathrm{Fe}$ in the sediment with different redox potential and shrimp stocking densities at the initial and day-35.

Note. $\square=$ Initial; $\square=\mathrm{LD} ; \square=\mathrm{HD}$

sediment in all treatments in this study were more than $4 \mathrm{mg} / \mathrm{L}$. However, possible explanation was described by Pakhomova et al. (2007) who demonstrated that on a time scale of single chamber incubation, manganese flux in the sediment-water interface did not depend on the redox condition, but was rather influenced by the concentration gradient between pore water and bottom water. Furthermore, the authors also pointed out that in this situation the rate of manganese oxidation was much lower than the rate of release from the sediment. In contrast to $\mathrm{Mn}$, no significant change of total Fe concentrations in the sediments was observed both during the experimental period and between the treatments.

This may relate to the possibility of the inhibition of Fe oxides reduction when Mn oxides are available in the environment. Furthermore, it was reported that the anoxic/oxic boundary at the sediment-water interface was efficient in oxidizing and trapping the iron, and that the dissolved oxygen concentration of more than $3.12 \mu \mathrm{g} . \mathrm{L}^{-1}$ resulted in no release of iron (Pakhomova et al., 2007). This strongly suggested that there was indeed no significant iron flux occurred in the sediments in this study.

The initial total $S$ concentration in the sediment with the lowest redox potential was significantly higher than those in other sediment redox potential tested $(P<0.01)$. Declined total $S$ concentrations were observed in all redox potential sediments after the experimental period with a range of $24-85 \%$. In the sediment with $-65 \mathrm{mV}$ and $108 \mathrm{mV}$, however, no significant change $(\mathrm{P}>0.05)$ was observed between the initial and the final total $S$ concentration as well as between the stocking density treatments. On the contrary, a significant reduction in the sediment total $\mathrm{S}$ was observed at $206 \mathrm{mV}$ sediment $(P=0.029)$. But, similar to other redox potential, there was also no significant difference $(P>0.05)$ observed between the stocking densities (Figure 2B). The decline of total $S$ concentrations in the sediment might relate to the contribution of oxygenation both by aeration and 
sediment bioturbation in the sediment-water interface that promotes the oxidation of sulphide $\left(\mathrm{S}^{2}\right.$ ) to the highly soluble sulphate $\left(\mathrm{SO}_{4}{ }^{2-}\right)$. This also suggested that most of the total $\mathrm{S}$ at higher redox potential sediment $(-65 \mathrm{mV}$ and $-104 \mathrm{mV})$ might have been oxidized to sulphate, thereby reducing the total S concentration in the sediment. On the other hand, previous studies clearly noted that the sulphate reduction to sulphide was inhibited when sufficient $\mathrm{Fe}$ and $\mathrm{Mn}$ oxides are available in the sediment (Middelburg and Levin, 2009).

\section{Water Profile}

Although depending on the sampling period, the effect of redox potential on the dissolved oxygen concentrations was more pronounced at a water depth of $85 \mathrm{~cm}$ (Table 1), where lower redox potential resulted in the lowest dissolved oxygen concentration (Figure 3a.). In contrast, stocking density significantly affected $(P=0.02-0.04)$ this parameters at all water depth except for 80 and 85 $\mathrm{cm}$ (Table 1). This can be seen by the notably lower DO concentrations at higher density compared to those in the lower density treatments at the water depth of $10 \mathrm{~cm}, 50 \mathrm{~cm}$, and $75 \mathrm{~cm}$ (Figure 3a). The general trend of DO concentrations during the experimentation seems to be similar for all treatments, which tend to decrease in time (Figure $3 b)$ and the level of DO reduction (the final - the initial DO) appeared to be significant ( $P=0.02-0.04)$ in all treatments except in treatment LD-65mV $(P>0.05)$. Dissolved oxygen concentration was clearly influenced by both shrimp density and the sediment redox potential. This confirmed previous studies, which reported the effect of stocking density, culture age, sediment redox and organic matter concentrations on the dissolved oxygen concentration in shrimp ponds (Xinglong and Boyd, 2006; Yuvamatemiya and Boyd, 2006).

The discrepancy in dissolved oxygen concentration between redox potential sediments, which getting higher as the water depth increased, suggesting the higher consumption of oxygen at the sediment-water interface layer. This might be attributed to the difference in the intensity of organic matter mineralization and benthic community metabolism in each sediment type. Decomposition processes of organic matter in the sediment consumed considerable amount of dissolved oxygen (Ebeling et al., 2006). Soil respiration is considered as one of the main factors that determine oxygen requirement in aquaculture ponds, which positively correspond to the concentration of organic matter and time of culture (Santa and Vinatea, 2007). The sediment oxygen demand (SOD), an indicator that represent mineralization processes in the sediment, at the end of a growing season could account for more than $50 \%$ of the total shrimp pond oxygen demand (Avnimelech and Ritvo, 2003; Santa and Vinatea, 2007). The partitioning of SOD in shrimp ponds comprise of about $84 \%$ for sulphide oxidation, 41 - $60 \%$ for carbon oxidation, 7 - 22\% for $\mathrm{Mn}$ reduction, 5 - 25\% for iron reduction and $13-26 \%$ for sulphate reduction (Avnimelech and Ritvo 2003).

Redox potential significantly affected all water quality parameters measured in this study except TAN concentration. However, the effect of this variable on the water quality parameters seems to depend on the sampling time (Table 2). Nonetheless, shrimp stocking density also affected all water quality parameters in this study except $\mathrm{H}_{2} \mathrm{~S}$ concentration. Significant interactions $(P<0.01)$ between redox potential and stocking densities were observed in nitrite and alkalinity concentrations, indicating simultaneous inter-correlated effects of these variables on nitrite and alkalinity. High shrimp stocking density resulted in significant increase $(\mathrm{P}<0.01)$ in TAN concentrations at each sediment redox potential tested (Figure 4a). Interestingly, nitrite concentrations in the $-206 \mathrm{mV}$ redox potential both in high and low density of shrimp were generally lower $(P<0.01)$ than the other redox potential treatments and this was consistent

Table 1. Repeated ANOVA P values of dissolved oxygen concentrations at $10 \mathrm{~cm}, 50 \mathrm{~cm}, 75 \mathrm{~cm}, 80 \mathrm{~cm}$ and $85 \mathrm{~cm}$ water depths.

\begin{tabular}{lccccc}
\hline \multicolumn{1}{c}{ Source } & \multicolumn{3}{c}{ P value } \\
\cline { 2 - 6 } & 10 & 50 & 75 & 80 & 85 \\
\hline Redox potential & 0.73 & 0.43 & 0.32 & 0.15 & 0.03 \\
Stocking density & 0.02 & 0.04 & 0.02 & 0.05 & 0.12 \\
Time & $<0.01$ & $<0.01$ & $<0.01$ & $<0.01$ & $<0.01$ \\
Redox potential $x$ stocking density & 0.84 & 0.87 & 0.84 & 0.82 & 0.83 \\
Redox potential $x$ time & 0.18 & 0.32 & 0.05 & 0.03 & $<0.01$ \\
Stocking density $x$ time & 0.03 & 0.26 & 0.12 & 0.16 & 0.17 \\
Redox potential $x$ stocking density $x$ time & 0.48 & 0.37 & 0.51 & 0.37 & 0.37 \\
\hline
\end{tabular}




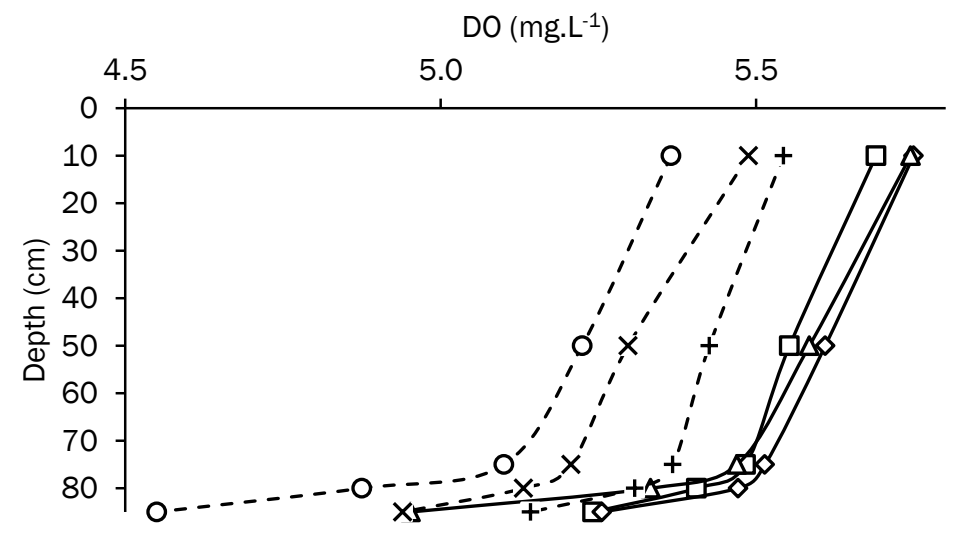

(a)

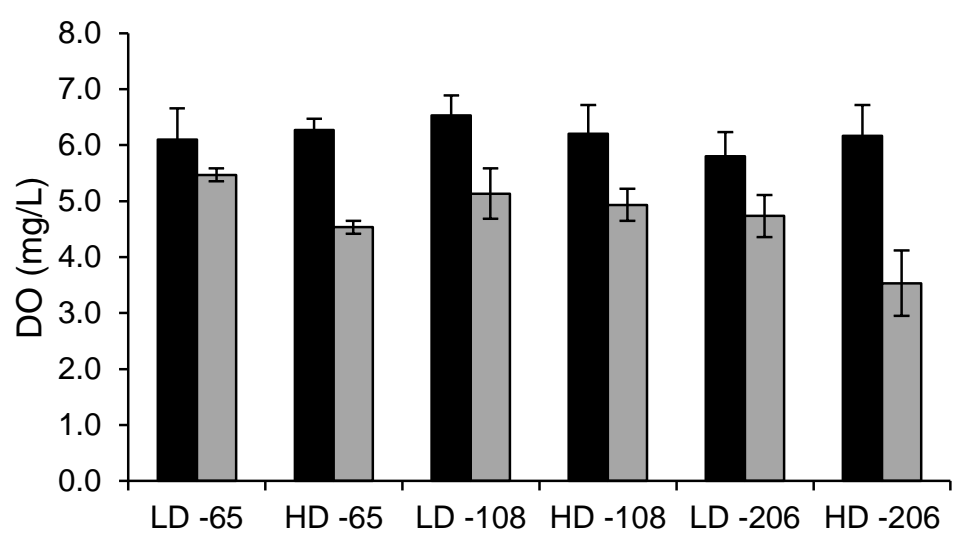

(b)

Figure 3. Dissolved oxygen concentrations in the shrimp culture water at different sediment redox potential and initial stocking densities: (a) at $10 \mathrm{~cm}, 50 \mathrm{~cm}, 75 \mathrm{~cm}, 80 \mathrm{~cm} 85 \mathrm{~cm}$ from the water surface and (b) at $85 \mathrm{~cm}$ depth on day-1 and day35.

Note. $\triangle-=$ LD -206; $\checkmark-=$ LD -108; $\square-\square=$ LD -65; - + - = HD -108; - - - - = HD -65; - O- = HD -206; $\mathbf{\square}=$ Day $1 ; \square=$ Day 35

throughout the experimental period (Figure 4b). Nitrate concentration seemed to progressively increase $(\mathrm{P}<0.01)$ in time with the treatments with high stocking density showing higher concentrations compared to the low stocking density. Dissolved inorganic nitrogenous waste accumulation in the water column appears to depend on both sediment redox potential and shrimp stocking density. The positive correlation between nitrogenous waste concentration and shrimp density has been reported in previous studies (Arnold et al., 2009). The increase in shrimp density leads to higher intensity of feed loaded into the culture system, and therefore increasing the release of ammonia as the metabolic by-product of the digested protein and as the mineralization product of organic matter in unconsumed feed and fecal materials.

When ammonia is released into the water, it may undergo various nitrogen conversion pathways, mostly carried out by microbial processes. These include nitrogen assimilation, nitrification, denitrification, and anaerobic ammonia oxidation (annamox) (Ebeling et al., 2006). Interestingly, redox potential of the sediment seems to have significant impact on the dissolved inorganic nitrogen profile in this study. This was possibly caused by the effect of redox potential on the dominant nitrogen conversion pathways in the sediment, which subsequently affected the composition of the inorganic $\mathrm{N}$ species in the water. Ammonia and nitrite oxidation in nitrification processes as well as ammonia assimilation in heterotrophic processes prevailed in highly aerobic environment, whereas $\mathrm{N}$ conversion through denitrification and anaerobic ammonia oxidation (annamox) are more likely to take place in anaerobic environment. The consistently lower nitrite concentrations in the $-206 \mathrm{mV}$ sediment throughout the experimental period might be related to denitrification and annamox as the primary $\mathrm{N}$ 
Table 2. Repeated ANOVA $P$ values of $\mathrm{pH}$ and the concentrations of total ammoniacal nitrogen (TAN), $\mathrm{NO}_{2}, \mathrm{NO}_{3}, \mathrm{H}_{2} \mathrm{~S}$ and alkalinity in the shrimp culture water.

\begin{tabular}{|c|c|c|c|c|c|c|}
\hline \multirow{2}{*}{ Source } & \multicolumn{6}{|c|}{$P$ value } \\
\hline & TAN & $\mathrm{NO}_{2}$ & $\mathrm{NO}_{3}$ & $\mathrm{H}_{2} \mathrm{~S}$ & $\mathrm{pH}$ & Alkalinity \\
\hline Redox potential & 0.12 & $<0.01$ & $<0.01$ & $<0.01$ & $<0.01$ & $<0.01$ \\
\hline Stocking density & $<0.01$ & $<0.01$ & $<0.01$ & 0.67 & $<0.01$ & $<0.01$ \\
\hline Time & $<0.01$ & $<0.01$ & $<0.01$ & $<0.01$ & $<0.01$ & $<0.01$ \\
\hline Redox potential $x$ stocking density & 0.74 & $<0.01$ & 0.42 & 0.38 & 0.32 & $<0.01$ \\
\hline Redox potential $x$ time & $<0.01$ & $<0.01$ & $<0.01$ & $<0.01$ & 0.04 & $<0.01$ \\
\hline Stocking density $x$ time & $<0.01$ & $<0.01$ & $<0.01$ & 0.68 & $<0.01$ & $<0.01$ \\
\hline Redox potential $x$ stocking density $x$ time & $<0.01$ & $<0.01$ & 0.35 & 0.37 & 0.36 & 0.57 \\
\hline
\end{tabular}
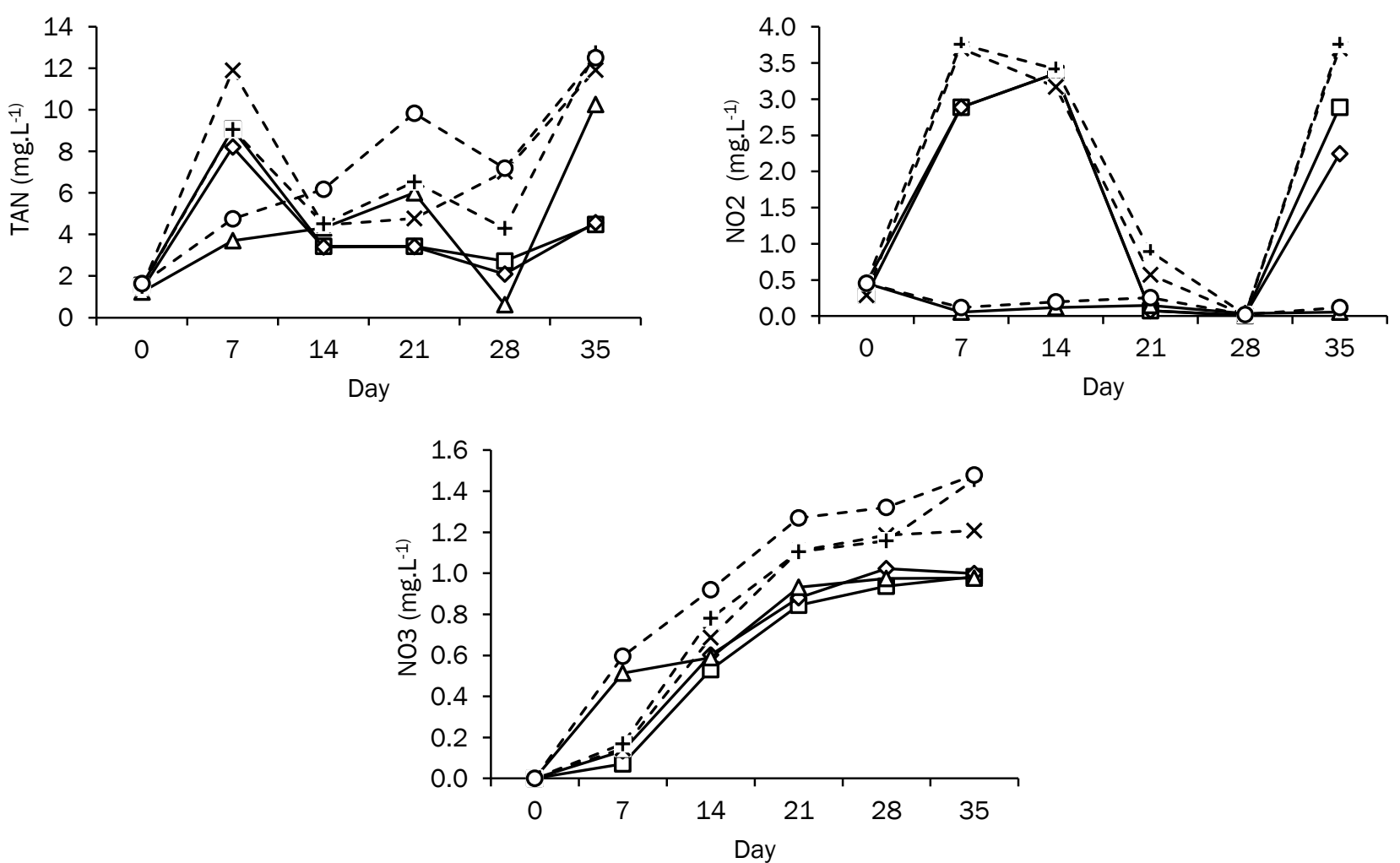

Figure 4. Inorganic $\mathrm{N}$ species concentrations in the shrimp culture water at different sediment redox potential and initial stocking densities for 35 days of experimentation: (A) total ammoniacal nitrogen (TAN), (B) Nitrite, (C) Nitrate.

Note. $\checkmark-=$ LD -206; $\curlyvee=$ LD -108; $\square-$ - = LD -65; - + - = HD -108; - - - - = HD -65; - O- - = HD -206

conversion pathways compared to other redox potential treatments, which was likely dominated by nitrification. The lower oxygen concentration in the $206 \mathrm{mV}$ sediment might promote ammonia conversion through denitrification and annamox, which used nitrite as an electron donor (Koeve dan Kahler, 2010) and thereby releasing nitrogen gas and nitrate (in annamox conversion).

On day 21 of experimentation, there was no significant difference $(\mathrm{P}>0.05)$ in $\mathrm{H}_{2} \mathrm{~S}$ concentrations observed between treatments. However, on day-35 significant differences $(P<0.01)$ were observed in this parameter. The effect of redox potential on $\mathrm{H}_{2} \mathrm{~S}$ concentration seemed to be more pronounced than that of stocking density. Figure 5 showed that on day-35, the $-206 \mathrm{mV}$ redox potential treatments both at high and low shrimp density resulted in the highest $(P<0.01) \mathrm{H}_{2} \mathrm{~S}$ concentrations. The increase of hydrogen sulphide concentration at $-206 \mathrm{mV}$ sediment might be explained by two possibilities, i.e. the increase of organic materials mineralization and the increase of sulphate reduction in this environment. However, the later seems to be more relevant because there was no significant difference in $\mathrm{H}_{2} \mathrm{~S}$ concentrations between the stocking densities, which strongly determine the quantity of feed input into the system. Although sulphate 
reduction might be inhibited by the presence of $\mathrm{Mn}$ and $\mathrm{Fe}$ oxides in the sediment (Middelburg and Levin, 2009), the relatively constant and low concentrations of total $\mathrm{Mn}$ and $\mathrm{Fe}$ in -206 mV sediments compared to other sediments might suggest that the reduction of $\mathrm{Mn}$ and Fe oxides in this environment had reached its saturation. Consequently, sulphate reduction commenced to intensify leading to the increase of $\mathrm{H}_{2} \mathrm{~S}$ accumulation in the water.

The -206 mV sediment at both stocking densities showed constantly higher $(P<0.01)$ alkalinity compared with other redox potential treatments and the differences were more pronounced after day-7 of experimentation (Figure $6)$. Total alkalinity might relate to the ammonia conversion pathways that occur in the water. Some of the $\mathrm{N}$ conversion pathways in the water, such as nitrification, heterotrophic ammonia assimilation and photoautotrophic $\mathrm{N}$ conversion (when nitrate is used as $\mathrm{N}$ source) require alkalinity (bicarbonate), and some, such as denitrification, release alkalinity as one of the end products (Ebeling et al., 2006; Koeve and Kahler, 2010; Zhou, 2007). In the present study, the relatively constant total alkalinity concentrations in the $-206 \mathrm{mV}$ sediment confirm the possibility of $\mathrm{N}$ conversion through denitrification and annamox. Ebeling et al. (2006) noted that denitrification yields $1.0 \mathrm{~mol}$ of hydroxyl ion for each mol of nitrate reduced, and therefore contribute to the total alkalinity in the water. On the other hand, although anaerobic ammonia oxidation requires bicarbonate in its process, the requirement

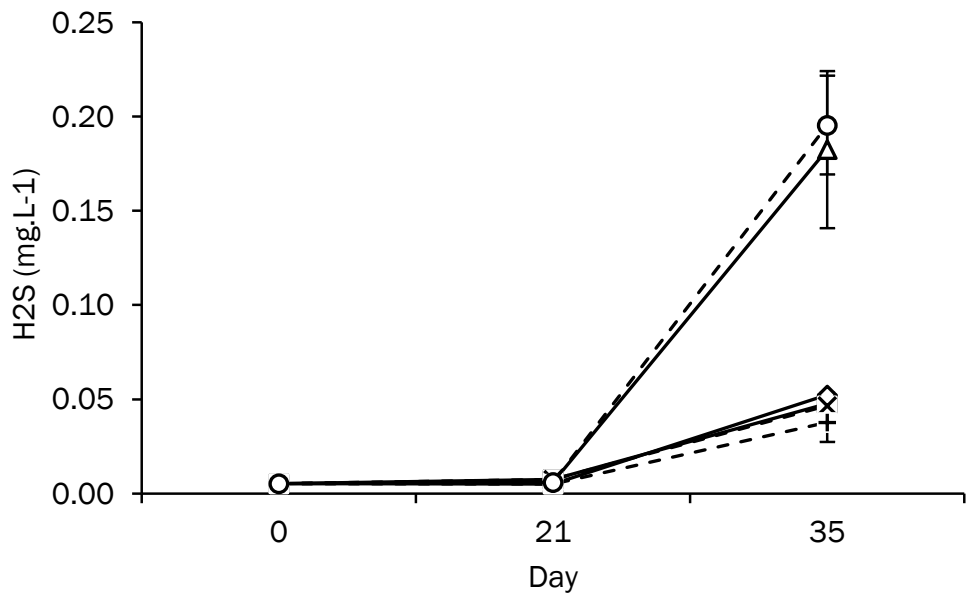

Figure 5. Sulphide $\left(\mathrm{H}_{2} \mathrm{~S}\right)$ concentrations at day-0, day-21 and day-35 in the shrimp culture water at different sediment redox potential and initial stocking densities.

Note. $\neg-=$ LD -206; $\prec=$ LD -108; $\square-\square=$ LD -65; - + - = HD -108; - - - - = HD -65; - O- - = HD -206

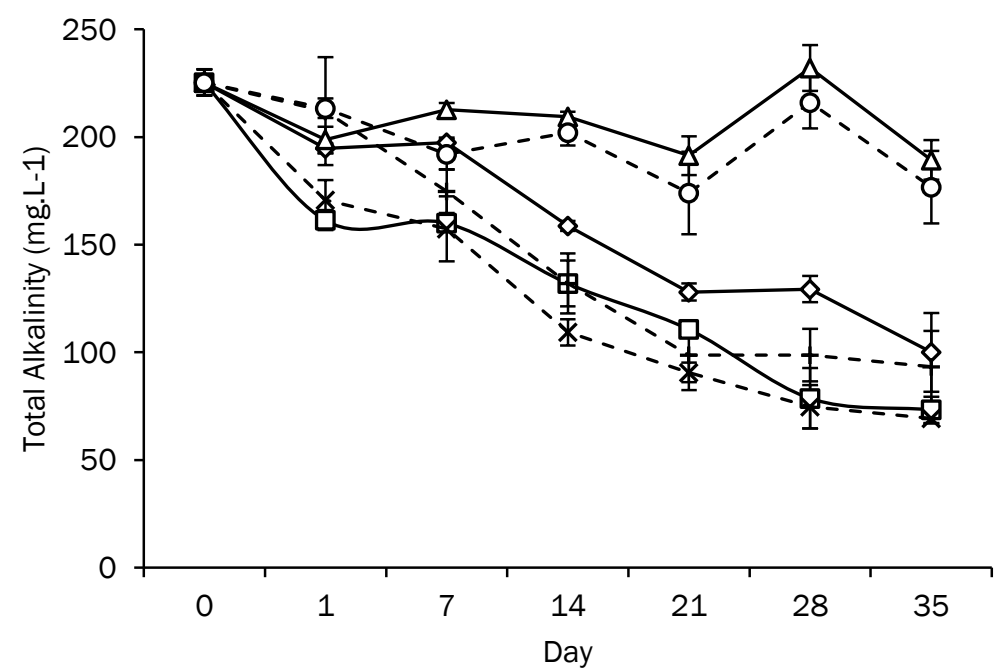

Figure 6. Total alkalinity concentrations in the shrimp culture water with different sediment redox potential and initial stocking densities during 35 days of experimentation period.

Note. $\triangle-=$ LD -206; $\curlyvee=$ LD -108; $\square-\square=$ LD -65; - + - = HD -108; - - - - = HD -65; - O- - = HD -206 


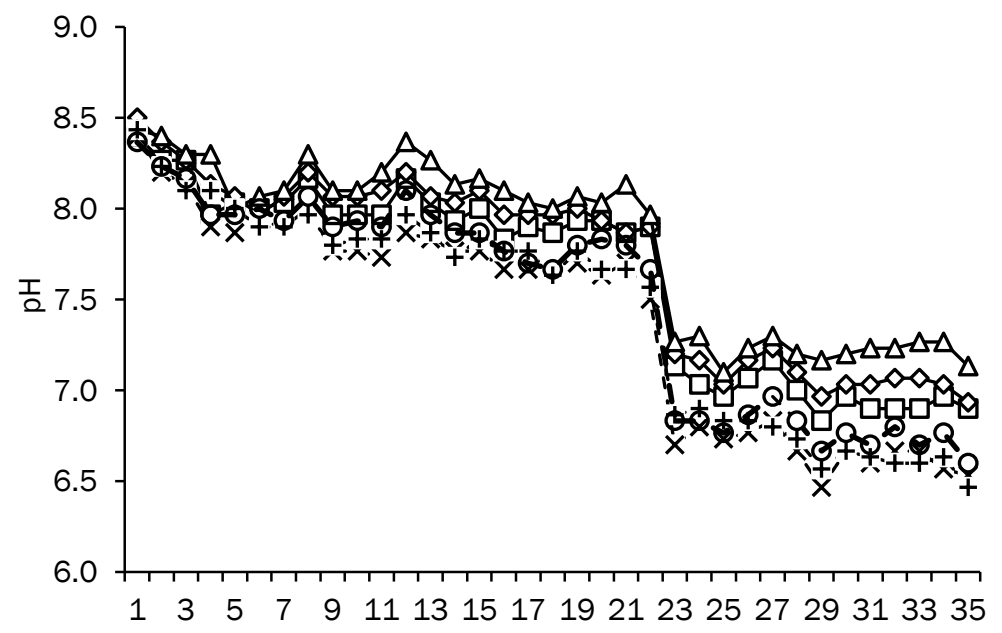

Day

Figure 7. $\mathrm{pH}$ value in the shrimp culture water with different sediment redox potential and initial stocking densities during 35 days of experimentation period.

Note. $\triangle-=$ LD -206; $\curlyvee=$ LD -108; $\square \square-=$ LD -65; - + - = HD -108; - - - - = HD -65; - O- - HD -206

is not as high as that in nitrification. To oxidize ammonia into nitrate, nitrification requires about $1.97 \mathrm{~mol}$ of bicarbonate (Ebeling et al., 2006), which is almost 30 times higher than that of annamox which only requires $0.07 \mathrm{~mol}$ of bicarbonate per mol of ammonia.

As the experimental period proceeded, water $\mathrm{pH}$ tended to decrease. Nevertheless, the level of reduction seemed to be affected by both shrimp density and sediment redox potentials, i.e. the lower the sediment redox potential and the stocking density the lower the $\mathrm{pH}$ reduction (Figure 7.). The $\mathrm{pH}$ values were significantly affected $(\mathrm{P}=0.04)$ by both variables tested in this study. The decline of $\mathrm{pH}$ throughout the experimentation might relate to the increase of $\mathrm{CO}_{2}$ concentrations along with the increase of shrimp biomass and microbial activities. The consistently higher total alkalinity in -206 mV sediments compared to other treatments might justify the considerably higher $\mathrm{pH}$ in these treatments.

\section{Conclusion}

Redox potential of the sediment clearly affected the total concentration of some major metal elements, which functioned as terminal electron acceptors in subsequent anaerobic respiration such as $\mathrm{Mn}$, Fe, and S. Conversely, shrimp density strongly affected all water quality parameters measured in this study except $\mathrm{H}_{2} \mathrm{~S}$ concentration. Redox potential of sediments also demonstrated significant effects on all water quality parameters except TAN concentration. Furthermore, the results clearly showed that $-206 \mathrm{mV}$ redox potential significantly reduced the dissolved oxygen concentration in the sediment-water interface and increased the generation of $\mathrm{H}_{2} \mathrm{~S}$ in water column. Thereby, this redox potential level is not advisable for shrimp culture system.

\section{Reference}

APHA. 2012. Standard methods for the examination of water and wastewater. United State of America: American Public Health Association, American Water Works Association and Water Environment Federation.

Arnold, S.J., Coman, F.E., Jackson, C.J. \& Groves, S.A., 2009. High-intensity, zero water-exchange production of juvenile tiger shrimp, Penaeus monodon: an evaluation of artificial substrates and stocking density. Aquaculture. 293(1):4248. doi: 10.1016/j.aquaculture.2009.03.049.

Arsana, I.G.K.D., Yahya, S., Lontoh, A.P. \& Pane, H., 2003. The relationship between early submerging and redox potential, ethylene production, and its effects on growth and yield of rice (Oryza sativa) on direct seeding system. Bul. Agron. 31(2): 37-41.

Avnimelech, Y. \& Ritvo, G. 2003. Shrimp and fish pond soils: processes and management. Aquaculture. 220:549-567. doi: 10.1016/S 0044-8486(02)00641-5. 
Avnimelech, Y., Ritvo, G \& Kochva, M. 2004. Evaluating the active redox and organic fractions in pond bottom soils: EOM, easily oxidized material. Aquaculture. 233: 283-292. doi: 10.1016/j.aquaculture.2003.10.039.

Biao, X. \& Kaijin, Y. 2007. Shrimp farming in China: operating characteristics, environmental impact and perspectives. Ocean Coast. Manage. 50(7): 538-550. doi: 10.1016/j.ocecoaman. 2007.02.006.

Blancheton, J.P., Attramadal, J.K., Michaudd, L., Roque d'Orbcastel, E. \& Vadstein, O., 2013, Insight into bacterial population in aquaculture systems and its implication. Aquacult Eng. 50: 30-39. doi: 10.1016/j.aquaeng.2012.11.009.

Boyd, C.E. 1995. Bottom soils, sediment, and pond aquaculture. Department of Fisheries and Allied Aquacultures at Auburn Un iversity. SpringerScience+Business Media, B.V. Alabama. P 89267.

Casillas-Hernández, R., Magallón-Barajas, F., PortilloClarck, G. \& Páez-Osuna, F., 2006. Nutrient mass balances in semi-intensive shrimp ponds from Sonora, Mexico using two feeding strategies: Trays and mechanical dispersal. Aquaculture, 258(1):289-298. doi: 10.1016/ j.aquaculture.2006.03.027.

Chien, Y.H. 1989. The Management of Sediment in Prawn Ponds. The Third Brazilian Shrimp Farming Congress. Joao Pessoa, PB, Brazil. p: 219-243.

De Schryver, P. \& Vadstein, O. 2014. Ecological theory as a foundation to control pathogenic invasion in aquaculture. The ISME J. 8(12): 2360-2368. doi: 10.1038/ismej.2014.84.

Ebeling, J.M., Timons, M.B. \& Bisogni, J.J., 2006. Engineering analysis of the stoichiometry of photoautotrophic, autotrophic, and heterotrophic removal of ammonia-nitrogen in aquaculture systems. Aquaculture. 257:246358. doi:10.1016/j.aquaculture. 2006.03.019.

Ellis, M.S., 1992. Oxygen, carbon and sulfur cycling in the sediments of hypereutrophic mesocosms (shrimp mariculture ponds). Thesis. Texas A\&M University. Texas. 152 pp.

FAO. 2015. Fishery statistical collections: Global aquaculture production (online queiry). Available at: http://www.fao.org/figis/servlet/ SQServlet?file=/work/FIGIS/prod/webapps/fig is/temp/hqp_5963274033712889334.xml\&o uttype=html. Accessed 29 Juni 2015.
FAO. 2013. Report of the FAO/MARD Technical workshop on early mortality syndrome (EMS) or acute hepatopancreatic necrosis syndrome (AHPNS) of cultured shrimp (UNDER TCP/VIE/3304). Fisheries and Aquaculture Report No. 1053. Hanoi, Vietnam, 25-27 June 2013. The Food and Agriculture Organization of the United Nation. 54 pp.

Flegel, T.W., 2015. Current status of shrimp diseases in Asia. Aquaculture Magazine April/May 2015. Available at: <http://www.aquaculturemag.com/magazine/a pril-may/2015/05/01/current-status-of-shrimp -diseases-in-asia. Accessed 17 Augst. 2015.

Horwitz., W. (Ed). 2002. Official methods of analysis of AOAC International, seventeenth ed. AOAC International. Maryland, USA. 771 pp.

Koeve, W. \& Kähler, P., 2010. Heterotrophic denitrification vs. autotrophic anammox quantifying collateral effects on the oceanic carbon cycle. Biogeosciences. 7: 2327-2337. doi: 10.5194/bg-7-2327-2010.

Krummenauer, D., Cavalli, R.O., Ballester, E.L. \& Wasielesky, W., 2010. Feasibility of Pacific white shrimp Litopenaeus vannamei culture in southern Brazil: effects of stocking density and a single or a double CROP management strategy in earthen ponds. Aquac. Res. 41(2): 240-248. doi: 10.1111/j.1365-2109.2009.02 326.x.

Leaño, E.M. \& Mohan, C.V., 2012. Disease Advisory: Early Mortality Syndrome (EMS)/Acute Hepatopancreatic Necrosis Syndrome (AHPNS): An emerging threat in the Asian shrimp industry. NACA. Bangkok, Thailand

Lin, Y.F., Jing, S.R., Lee, D.Y., Chang, Y.F. \& Sui, H.Y., 2010. Constructed wetlands for water pollution management of aquaculture farms conducting earthen pond culture. Water Environ. Res. 82(8):759-768. doi: 10.2175/106143010X1 2609736966685 .

Middelburg, J.J. \& Levin, L.A., 2009. Coastal hypoxia and sediment biogeochemistry. Biogeosciences. 6:1273-1293. doi: 10.5194/ bg-6-1273-2009.

Molnar, N., Welsh, D.T., Marchand, C., Deborde, J. \& Meziane, T., 2013. Impacts of shrimp farm effluent on water quality, benthic metabolism and $\mathrm{N}$-dynamics in a mangrove forest (New Caledonia). Estuar. Coast. Shelf Sci. 117: 1221. doi: 10.1016/j.ecss. 2012.07.012. 
Mydlarz, L.D., Jones, L.E. \& Harvell, C.D., 2006. Innate immunity, environmental drivers, and disease ecology of marine and freshwater invertebrates. Annu. Rev. Ecol. Evol. Syst. 251288. doi: 10.1146/annurev.ecolsys.37.0913 05.110103 .

NACA, 2014. Thirteenth meeting of the asia regional advisory groupon aquatic animal health: report of the meeting. The Network of Aquaculture Centres in Asia-Pacific. Bangkok, Thailand.

Nimrat, S., Suksawat, S., Maleeweach, P. \& Vuthiphandchai, V., 2008. Effect of different shrimp pond bottom soil treatments on the change of physical characteristics and pathogenic bacteria in pond bottom soil. Aquaculture. 285(1):123-129. doi: 10.1016/j. aquaculture.2008.08.020.

Nóbrega, G.N., Otero, X.L., Macías, F. \& Ferreira, T.O., 2014. Phosphorus geochemistry in a Brazilian semiarid mangrove soil affected by shrimp farm effluents. Environ. Monit. Assess. 186(9):5749-5762. doi:10.1007/s10661-0143817-3.

Páez-Osuna, F. \& Ruiz-Fernández, A.C., 2005. Environmental load of nitrogen and phosphorus from extensive, semiintensive, and intensive shrimp farms in the Gulf of California ecoregion. Bull. Environ. Contamination Toxicol. 74(4):681-688. doi : 10.1007/s00128-005-06 $37-8$

Pakhomova, S.V., Hall, P.O.J, Kononets, M.Y., Rozanov, A.G., Tengberg, A. \& Vershinin, A.V., 2007. Fluxes of iron and manganase across the sediment-water interface under various redox conditions. Mar. Chem. 107:319-331. doi: 10.1016/j.marchem. 2007.06.001.

Rayment, G.E. \& F.R. Higginson. 1992. Soil chemical methods-Australsia. CSIRO Publishing. Australia.

Ritvo, G., Dixon, J.B., Lawrence, A.L., Samocha, T.M., Neill, W.H. \& Speed, M.E., 1998. Accumulation of chemical elements in Texas shrimp pond soils. J. World Aquacul. Society, 29(4):422-431. doi: 10.1111/j.1749-7345.1998.tb0066 6.x.

Sahu, B.C., Adhikari, S. \& Dey, L., 2013. Carbon, nitrogen and phosphorus budget in shrimp (Penaeus monodon) culture ponds in eastern India. Aquacult. Int. 21(2): 453-466. doi: 10.10 07/s10499-012-9573-x.

Santa, K.D. \& Vinatea, L., 2007. Evaluation of respiration rates and mechanical aeration requirements in semi-intensive shrimp Litopenaeus vannamei culture ponds. Aquacult. Eng. 36(1):73-80. doi: 10.1016/j.aquaeng. 2006.07.002.

Saraswathy, R., Muralidhar, M., Kailasam, M., Ravichandran, P., Gupta, B.P., Krishnani, K.K., Ponniah, A.G., Sundaray, J.K., Panigrahi, A. \& Nagavel, A., 2013. Effect of stocking density on soil, water quality and nitrogen budget in Penaeus monodon (Fabricius, 1798) culture under zero water exchange system. Aquaculture Res. 44(10):1578-1588. doi: 10.1111/j.1365-2109. 2012.03165.x.

Sindelar, H.R., Brown, M.T. \& Boyer, T.H., 2015. Effects of natural organic matter on calcium and phosphorus co-precipitation. Chemosphere. 138: 218-224. doi: 10.1016/j. chemosphere.2015.05.008.

USDA. 2014. Kellogg Soil Survey Laboratory Methods Manual: Soil Survey Investigations Report No. 42. United State Departement of Agriculture, Linkold, Nebraska.

Walker, P.J. \& Winton, J.R., 2010. Emerging viral diseases of fish and shrimp. Vet. Res. 41(6): 41-51. doi: 10.1051/vetres/2010022.

Wilding, T. A. 2012. Changes in sedimentary redox associated with mussel (Mytilus edulis L.) farms on the West-Coast of Scotland. Plos One. 7(9), e45159. doi: 10.1371/journal. pone.0045159.

Xinglong, J. \& Boyd, C.E., 2006. Relationship between organic carbon concentration potential pond bottom soil respiration. Aquacult. Eng. 35: 147-151. doi: 10.1016 /j.aquaeng. 2005.10.002.

Yuvanatemiya, V. \& Boyd, C.E. 2006. Physical and chemical changes in aquaculture pond bottom soil resulting from sediment removal. Aquacult. Eng. 35: 199-205. doi: 10.1016/j.aquaeng.2 006.02 .001

Zhou, Q., Li, K., Jun, X. \& Bo, L., 2009. Role and functions of beneficial microorganisms in sustainable aquaculture. Bioresource Technology. 100(16):3780-3786. doi: 10.1016 j.biortech. 2008.12.037.

Zhou, S. 2007. Stoichiometry of biological nitrogen transformations in wetlands and other ecosystems. Biotechnol. J. 2:497-507. doi: 10.1002/biot.200600078. 